\title{
Stabilising nanofluids in saline environments
}

Sarmad Al-Anssari ${ }^{1,2^{*}}$, Muhammad Arif ${ }^{3,4}$, Shaobin Wang ${ }^{1}$, Ahmed Barifcani ${ }^{1,3}$, Stefan Iglauer $^{3}$

${ }^{1}$ Department of Chemical Engineering, Curtin University, Kent Street, 6102 Bentley, Australia

${ }^{2}$ Department of Chemical Engineering, College of Engineering, University of Baghdad, Iraq

${ }^{3}$ Department of Petroleum Engineering, Curtin University, 26 Dick Perry Avenue, 6151

${ }^{4}$ University of Engineering and technology, Lahore, 54890, Pakistan.

Kensington, Australia

*Corresponding author

Phone: +61 892667703

Fax: +61 892667063

Email: sarmad.al-anssari@postgrad.curtin.edu.au

\begin{abstract}
Nanofluids (i.e. nanoparticles dispersed in a fluid) have tremendous potential in a broad range of applications, including pharmacy, medicine, water treatment, soil decontamination, or oil recovery and $\mathrm{CO}_{2}$ geo-sequestration. In these applications nanofluid stability plays a key role, and typically robust stability is required. However, the fluids in these applications are saline, and no stability data is available for such saltcontaining fluids. We thus measured and quantified nanofluid stability for a wide range of nanofluid formulations, as a function of salinity, nanoparticle content and various additives, and we investigated how this stability can be improved. Zeta sizer and dynamic light scattering (DLS) principles were used to investigate zeta potential and particle size
\end{abstract}


distribution of nanoparticle-surfactant formulations. Also scanning electron microscopy was used to examine the physicochemical aspects of the suspension.

We found that the salt drastically reduced nanofluid stability (because of the screening effect on the repulsive forces between the nanoparticles), while addition of anionic surfactant improved stability. Cationic surfactants again deteriorated stability. Mechanisms for the different behaviour of the different formulations were identified and are discussed here.

We thus conclude that for achieving maximum nanofluid stability, anionic surfactant should be added.

Keywords: Silica, nanoparticle, surfactant, cationic, anionic, stability, zeta potential.

\section{Introduction}

Nanoparticles (NPs) have been widely investigated for many scientific and industrial applications, spanning from drug delivery [1], medicine [2, 3], polymer composites [4], lubrication [5], and metal ion removal [6] to carbon geosequestration [7] and enhanced oil recovery [8-11]. Typically, thermodynamic properties of the base fluids are significantly modified by the suspended nanoparticles; thus specific and attractive properties can be tailored, including viscosity, rheology [5], thermal conductivity [12, 13] and interfacial tension [14].

The successful application of NPs in saline environments (e.g. subsurface operations) requires dispersible, stable, inexpensive and injectable nano-suspensions to facilitate a uniform transport and migration of nanofluids in porous medium. However, in subsurface formations, many factors including temperature, pressure, heterogeneity, and complexity of reservoirs can dramatically impact the effectiveness of nanofluids. Increased temperature, for example, increases the kinetic energy of nanoparticles and consequently the collision rate between nanoparticles and eventually reducing nanofluid stability [15]. Another important pertinent challenge is the nanofluid stability is saline brine. It is well established that the brine salinity in subsurface formations and deep saline aquifers varies significantly and can reach very high levels $[16,17]$. Under such saline environments, electrolytes (e.g. $\mathrm{NaCl}$ ) can dramatically reduce the repulsive forces between NPs and 
consequently accelerate particles flocculation and coagulation due to the increased rate of collision and coalescences of NPs in the suspension [18] leading to phase separation. In addition, it is known that the dispersion and stability of NPs in the base fluid can be improved by adding surface active agents such as surfactants [10, 19], polymers [4], or surfactant-polymer combination [20] to the base fluid to adjust their properties for a specific application through the formation of surfactant coated nanoparticles.

A number of studies investigated the adsorption of surfactants onto NPs that were dispersed in DI water or dilute brine using contact angle measurements, adsorption isotherms of surfactant on nanoparticles, zeta potential measurements and dispersion stability in terms of nanoparticles and surfactant concentrations [19-24]. Despite the published data in the previous studies, there is no reported data about surfactantnanosuspension dispersibility and stability at high salinity condition which is, nevertheless, very important. Thus in this study, we investigate the ability of anionic and cationic surfactants to disperse and stabilize silica NPs at high salinity conditions by measuring zeta potential and particle size of various nanofluid suspensions as a function of brine salinity (ranging from $0 \mathrm{wt} \% \mathrm{NaCl}-5 \mathrm{wt} \% \mathrm{NaCl}$ ). Sodium Dodecylsulfate (SDS) and Hexadecyltrimethylammonium Bromide (CTAB) are used as anionic and cationic surfactants respectively. The results demonstrate that anionic surfactants lead to better stability of nanofluids in comparison to cationic surfactants. This work thus leads to recognition of suitable conditions which promote better stability of nanofluids in saline environments which in turn lead to better transport of nanoparticles in porous media.

\section{Experimental methodology}

\subsection{Materials}

$\mathrm{SiO}_{2}$ nanoparticles (porous spheres, $\rho=2.2-2.6 \mathrm{~g} \mathrm{~cm}^{-3}$ ) with a purity of $99 \mathrm{~mol} \%$ and a primary particle diameter of 5-10 $\mathrm{nm}$ were supplied as nano-powder by SIGMAALDRICH, Australia. Two surfactants, a) anionic [Sodium Dodecylsulfate, SDS, Sigma-

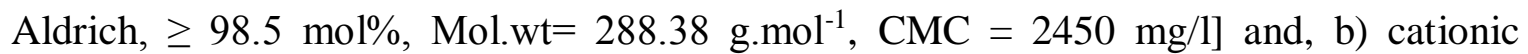
[Hexadecyltrimethylammonium Bromide, CTAB, Sigma-Aldrich, $\geq 98$ mol\%, Mol.wt= 364.45 g. $\left.\mathrm{mol}^{-1}, \mathrm{CMC}=350 \mathrm{mg} / \mathrm{l}\right]$ were used in this study. These two surfactants were chosen for their commercial availability and the widely known properties. Binks and Rodrigues [25] reported that the particular structure of ionic surfactants have no effect on 
the electrical properties of silica particles and thus the adsorption of mono or di-chain ionic surfactant on silica surface gives similar effects on nanoparticles surface charge.

Deionized (DI) water (Ultrapure from David Gray; conductivity $=0.02 \mathrm{mS} . \mathrm{cm}^{-1}$ ) was used to prepare $\mathrm{NaCl}$ ( $\geq 99.5 \mathrm{~mol} \%$ purity, from Scharlan) solutions, nanofluids, and surfactant solutions.

\subsection{Nanofluid formulation}

Surfactant coated nanoparticles were prepared by sonicating NPs in surfactants formulation with appropriate ratios. Various $100 \mathrm{~mL}$ surfactant solutions with varying surfactant concentrations $(0,245,735,980,1125,2450,4900$, and $7350 \mathrm{mg} / \mathrm{l})$ and $\mathrm{NaCl}$ concentrations $(0,0.1,0.5,1.0,1.5,2.0,2.5,3.0$ and $5.0 \mathrm{wt} \%)$ were prepared by adding the surfactant powder to brine and mixing with magnetic starrier for 2 hours [10]. Note that the measured critical micelles concentrations (CMCs) with DI water were 2380 and $355 \mathrm{mg} / \mathrm{l}$ for SDS [24, 26] and CTAB [27], respectively.

Subsequently, various nano-suspensions were prepared by mixing a range of silica dioxide NPs concentrations $(0.05 \mathrm{~g}, 0.10 \mathrm{~g}, 0.50 \mathrm{~g}, 1.00 \mathrm{~g}, 1.25 \mathrm{~g}, 1.50 \mathrm{~g}$ and $2.00 \mathrm{~g})$ with the aqueous phase (brine, DI water or surfactant solution) and sonicating (with a $300 \mathrm{VT}$ Ultrasonic Homogenizer/ BIOLOGICS instrument) for $15 \mathrm{~min}$ to homogenize the dispersion [28-31]. Such homogenisation is crucial for chemical stability as it is required for the zeta potential measurements, otherwise results may be biased [32]. The appearance of the dispersion was photographed at varied times when required to check the phase stability (further information in Supplementary material).

\subsection{Particle size, zeta potential and SEM measurements}

The physicochemical characteristics of NPs were studied using scanning electron microscopy (SEM, Zeiss Neon 40EsB FIBSEM), particles size distribution (PSD), and zeta potential $(\zeta)$ measurements. A dynamic light scattering (DLS), Zetasizer Nano ZS (Malvern Instruments, UK), was used to determine particles size distribution and the zeta potential of the nano-suspension. The direct observation is the intensity fluctuation due to the diffusion of particles undergoing Brownian motion by a laser beam [33], and this diffusion 
coefficient is then interpreted to a hydrodynamic diameter. Meanwhile, the surface electric charge can be estimated by zeta potential which is the measurable parameter related to the charge and electrical double layer of a solid surface in aqueous solution [34] and it is totally based on displacement of the charge in the electrical double layer due to a tangential shifting of liquid phase against the solid using external force [35].

In this study we kept the $\mathrm{pH}$ of the suspension at $\mathrm{pH}=6.25$ for all tested formulations. Three measurements were taken for each test, and the average value was evaluated. The standard deviation of measurements was $\pm 3 \mathrm{mV}$ however at relatively high salinity (> 1 $\mathrm{wt} \% \mathrm{NaCl}$ ) or around the isoelectric point (IEP), the standard deviation was higher (e.g. \pm 6 $\mathrm{mV})$.

\section{Result and discussion}

Improving the stability of silica nanodispersion at high salinity conditions is a key in subsurface applications. Ionic surfactant can significantly affect the surface charges of NPs and its aggregation process, and in turn the stability of nanofluids. Thus, despite the potential changes in nanofluids compositions upon injection into the treated medium in the particle field, we investigated the influence of cationic and anionic surfactants in an attempt to address the effectiveness of surfactants to improve the nanofluids stability in a saline environment.

\subsection{Characterization of $\mathrm{SiO}_{2}$ nanoparticles}

Silica nanoparticles can get dispersed in DI water owing to their inherent hydrophilicity. $\mathrm{SiO}_{2}$ nanoparticles have a porous, spherical structure. However, the scanning electron microscopy (SEM) image of a dried aqueous dispersion of NPs $\left(0.1 \mathrm{wt} \% \mathrm{SiO}_{2}\right.$ dispersed in DI water) depict the non-spherical nature of NPs due to the formation of aggregates from primary particles (Fig. 1). Further, size distribution measurements of the same nanofluid using dynamic light scattering (Fig. 2) confirms the formation of these aggregates since the average particle diameter was $84 \mathrm{~nm}$ with a considerable ratio of significantly bigger aggregates $\approx 0.75 \mu \mathrm{m}$. 


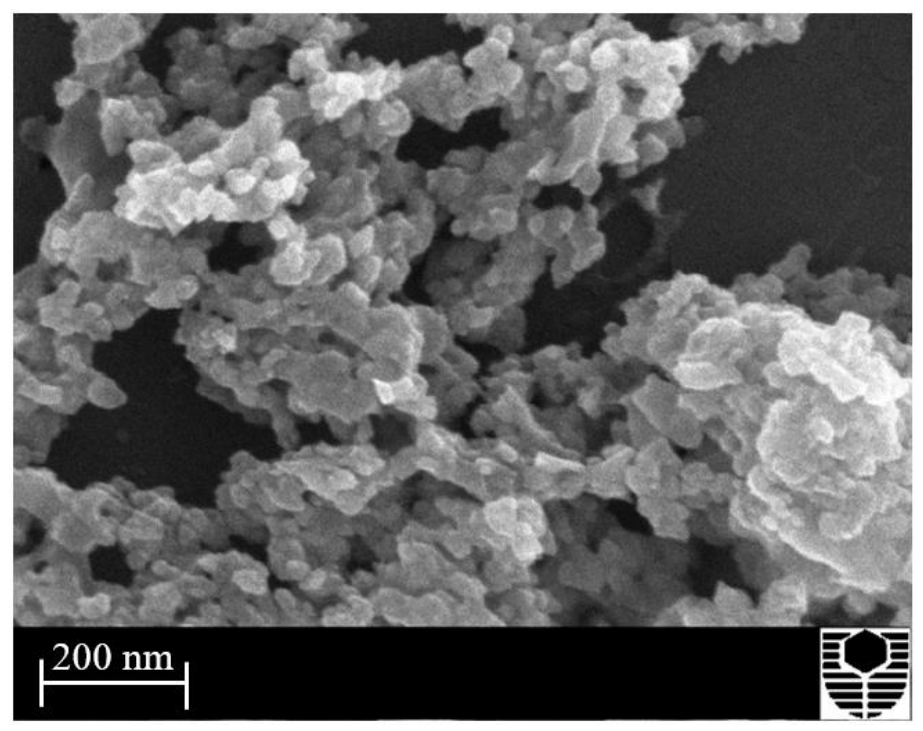

Fig. 1. SEM profile of $\mathrm{SiO}_{2}$ nanoparticles, ultrasonically dispersed in DI water, after drying.

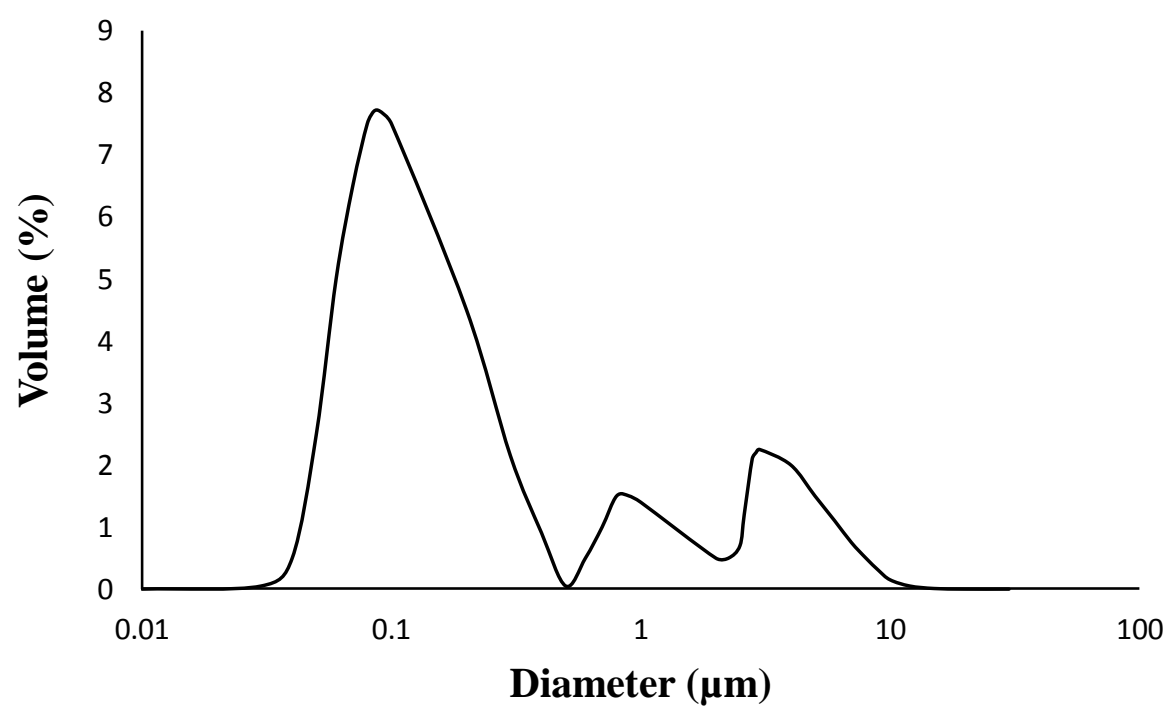

Fig. 2. Size distribution of $0.1 \mathrm{wt} \% \mathrm{SiO}_{2} \mathrm{NPs}$ ultrasonically dispersed in $\mathrm{DI}$ water $(\mathrm{pH}=$ 6.2) measured by dynamic light scattering (DLS) at ambient conditions.

Although, the efficient sonication process, both SEM image and size distribution measurements revealed the instability and the potential aggregation of silica NPs in DI water, yet the repulsive force between similarly charged NPs, the Brownian motion causes particles collision [36] and more collisions increase the possibility of NPs to stick with each other and forms small aggregates. Further, the dispersion condition are potentially more severe at higher NP load and in the presence of electrolyte. 


\subsection{Zeta potential as a function of salinity}

Salts including $\mathrm{NaCl}$ can destabilize particle dispersions by compressing the electrical double layer and screening the electrostatic repulsion force among NPs. Moreover, NP concentration (wt\% NP) can impact the stability of the colloid due to the increase in particles number per unit area which increase the collision rate between particles and thus the possibility of aggregates formation. As a consequence, it is essential to investigate the effect of suspension composition on the zeta potential of the nanofluid which is a stability scale for the colloid.

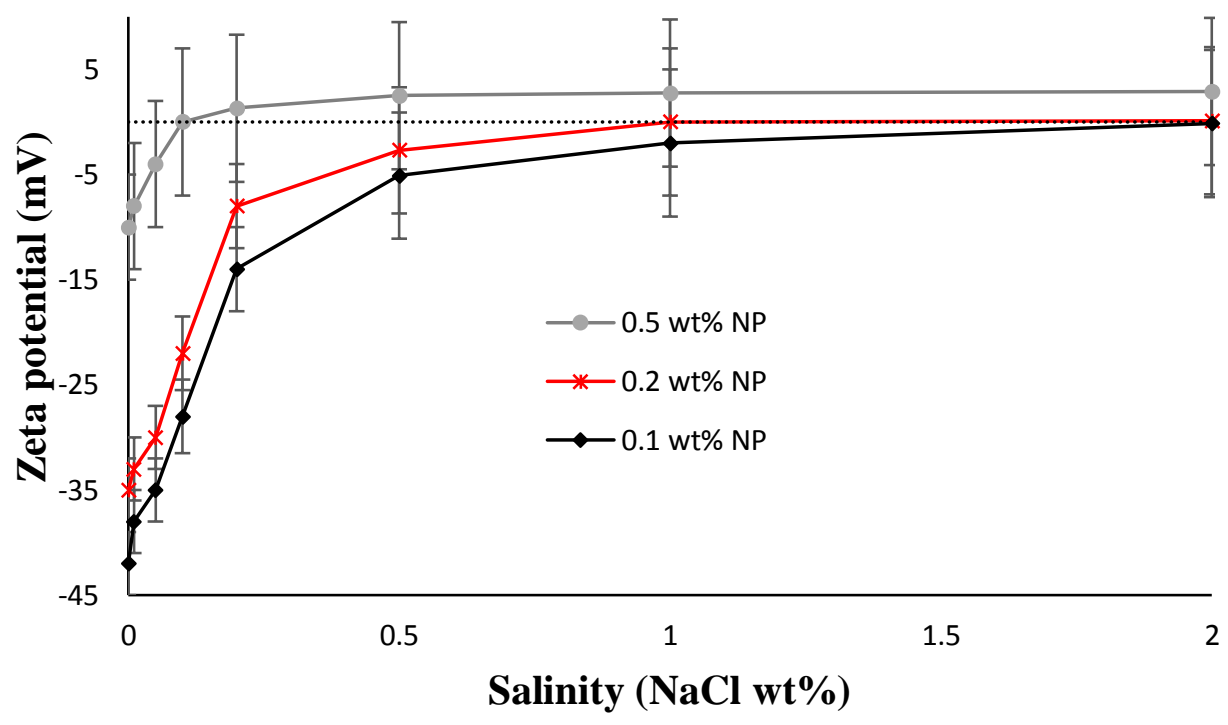

Fig. 3. Zeta potential of $\mathrm{SiO}_{2} \mathrm{NP}$ dispersion as function of base fluid salinity and NP concentration (at $23^{\circ} \mathrm{C}$ and a constant $\mathrm{pH}=6.25$ ).

Our results of zeta potential measurements (Fig. 3) demonstrated that both salt and NP concentrations had significant impact on zeta potential of nanofluids. A dramatic shift in zeta potential towards zero was observed with salinity increase for all NP loads (e.g. $\xi$ was changed from $-35 \mathrm{mV}$ to $-8 \mathrm{mV}$ when the salinity of $0.2 \mathrm{wt} \% \mathrm{NP}$ dispersion increased from $0 \mathrm{wt} \% \mathrm{NaCl}$ to $0.2 \mathrm{wt} \% \mathrm{NaCl}$ ). This is principally important since nanosuspension can only be stable when $| \pm \xi| \geq 30 \mathrm{mV}[11,31]$. Further, the inversion of surface charge (from negative to positive) was recorded for the $0.5 \mathrm{wt} \% \mathrm{NP}$ fluid as $\mathrm{NaCl}$ concentration increased $(\geq 0.1 \mathrm{wt} \% \mathrm{NaCl}$ ) due to the screening of surface charges of particles. These observations are consistent with the reported data at lower salt and nanoparticle concentrations $[37,38]$. 
Mechanistically, the increase of NP concentration increases the number of particles per unit area leading to the formation of agglomerates due to the increase in collisions rate between particles which forms a charge depletion region on particles surface [39] and consequently support the formation of aggregates.

\subsection{Surface activation of $\mathrm{SiO}_{2} \mathrm{NPs}$ by cationic surfactant}

The CTAB surfactant was used to study the effect of cationic surfactant on the stability of oppositely charged hydrophilic silica NPs. Despite the ability of CTAB to invert the negative surface charge of silica NPs to positive, a significant sediment was observed at the bottom side of the samples referring to an accelerated aggregation and sedimentation process in the suspension. The sediment height versus CTAB concentration (Fig. 4) was used to ascertain suspension instability.

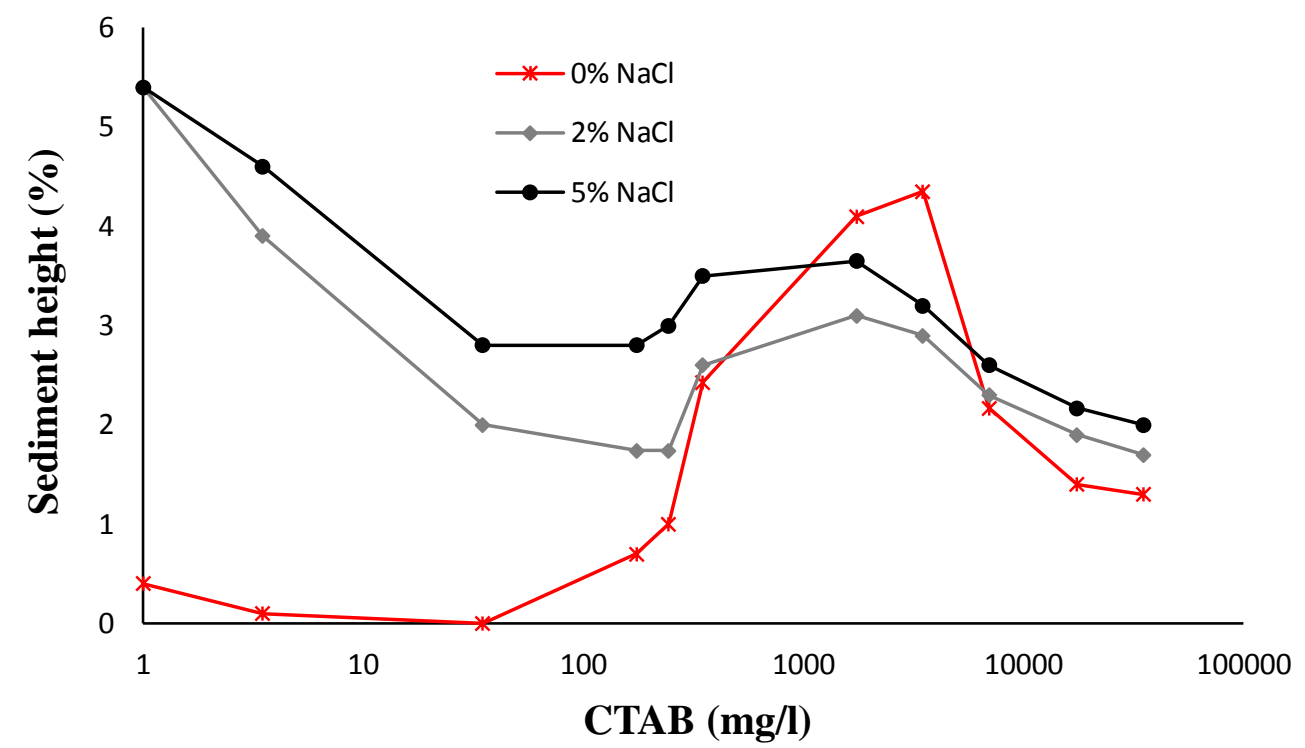

Fig. 4. Sediment height versus CTAB concentration after $72 \mathrm{~h}$, at different base fluid salinity for $0.1 \mathrm{wt} \% \mathrm{NP}$ nanofluid at $\mathrm{pH}=7$.

It was found that concentration of cationic surfactant had dramatic impact on aggregation processes of silica NPs at different salinities (Fig. 4). For nano-suspensions with saline base fluid ( $2 \mathrm{wt} \% \mathrm{NaCl}$ and $5 \mathrm{wt} \% \mathrm{NaCl}$ ), a significant sediment height ratios were recorded after $48 \mathrm{~h}$ at very low CTAB concentrations $(\leq 40 \mathrm{mg} / \mathrm{l} \approx 0.01 \mathrm{CMC})$. Mechanistically, salts including $\mathrm{NaCl}$ can screen the electrostatic repulsion forces between NPs and thus cause the NPs to stick to each other forming larger aggregates [40, 41]. These 
aggregates are heavier than NPs and easy to sediment rapidly by gravity. The increase of CTAB concentration (up to $200 \mathrm{mg} / \mathrm{l}$ ) reduced silica sediment height; however, further increase in cationic surfactant concentration ( $\geq 350 \mathrm{mg} / \mathrm{l}$, which is equivalent to CMC) leads to an increase and then a decrease in the sediment height when CTAB concentration become $\geq 1750 \mathrm{mg} / 1$ (5 CMC; Fig. 4). This fluctuation in sediment height is potentially related to the change in surface charges of NPs and thus particle hydrophobicity as CTAB concentration increases which consequently leads to the formation of rigid network of NPs.

For nano-suspension with DI water base fluid, no sedimentation was recorded at low CTAB concentrations ( $\leq 35 \mathrm{mg} / 1 \approx 0.1 \mathrm{CMC}$; Fig. 4). However, with the absence of surfactant $(0 \mathrm{mg} / \mathrm{l} \mathrm{CTAB})$, precipitation of slight amount of silica NP was recorded. Mechanistically, the aggregation of silica NPs dispersed in water is controlled by the density of silanol groups $(\mathrm{SiOH})$ at particle surface. As a results, at $\mathrm{pH}=6.25$, the particle surfaces are appreciably negatively charged owing to dissociation of surface silanol ( $\mathrm{SiOH})$ groups [42] and the repulsive forces between negatively charged NPs are strong enough to keep these NPs separated from each other.

\subsection{Interaction between NPs surface and cationic surfactant}

The adsorption of single chain cationic surfactant (CTAB) molecules on the hydrophilic silica NP can invert the surface charge form the initial negative to neutral and then positive values. Further, the positivity increases with cationic surfactant concentration (Fig. 5). This transition of surface charge explains the change in sedimentation height which refers to the interaction between NPs (Fig. 4). Typically, the highest sedimentation height represents the condition of neutral charge when zeta potential is close to the iso-electric point (IEP). 


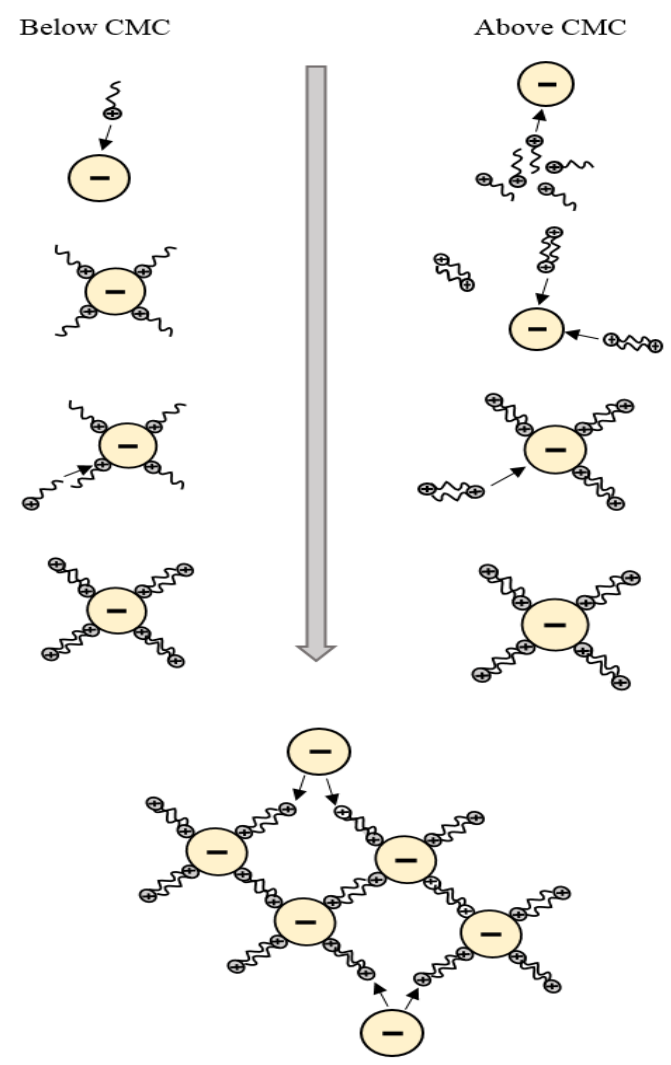

Fig. 5. Mechanisms of cationic molecules adsorption with surfactant concentration before and after reaching the critical micelles concentration (CMC).

Figure 5 proposed that a monolayer of adsorbed CTAB molecules is gradually form on the particle surface due to the electrostatic attraction between the positive head groups and the negative particle surface which neutralises the negative charges of the $\left(\mathrm{SiO}^{-}\right)$groups. Most of silica particles at this initial stage of cation adsorption are uncharged and thus remain relatively hydrophobic. Further increase in cation concentration forms a second layer of surfactant owing to the hydrophobic attraction between chains of adsorbed surfactant molecules in the monolayer and free monomers. The formation of the second layer produces totally positively charged nanoparticles owing to the coating with bilayer of cationic surfactant. Mechanistically, the positively charged CTAB groups adsorb on the negatively charged silica surface, thus neutralizing and subsequently positively charging the silica surface $[43,44]$.

Overall, the cationic surfactant demonstrated a potential ability to destabilize silica nanofluid particularly with the presence of electrolyte (Fig. 4 and 5). 


\subsection{Surface activation of $\mathrm{SiO}_{2} \mathrm{NPs}$ by anionic surfactant}

The SDS surfactant was used to study the effect of anionic surfactant on the stability of similarly charged hydrophilic silica NPs. Although previous studies reported that the addition of SDS to the nanofluid can supercharge the surface of silica particles leading to stronger negative charge and thus higher repulsive forces between NPs [19], our results demonstrated different agglomeration and sedimentation scenarios particularly with increased SDS and salt concentrations (Fig. 6).

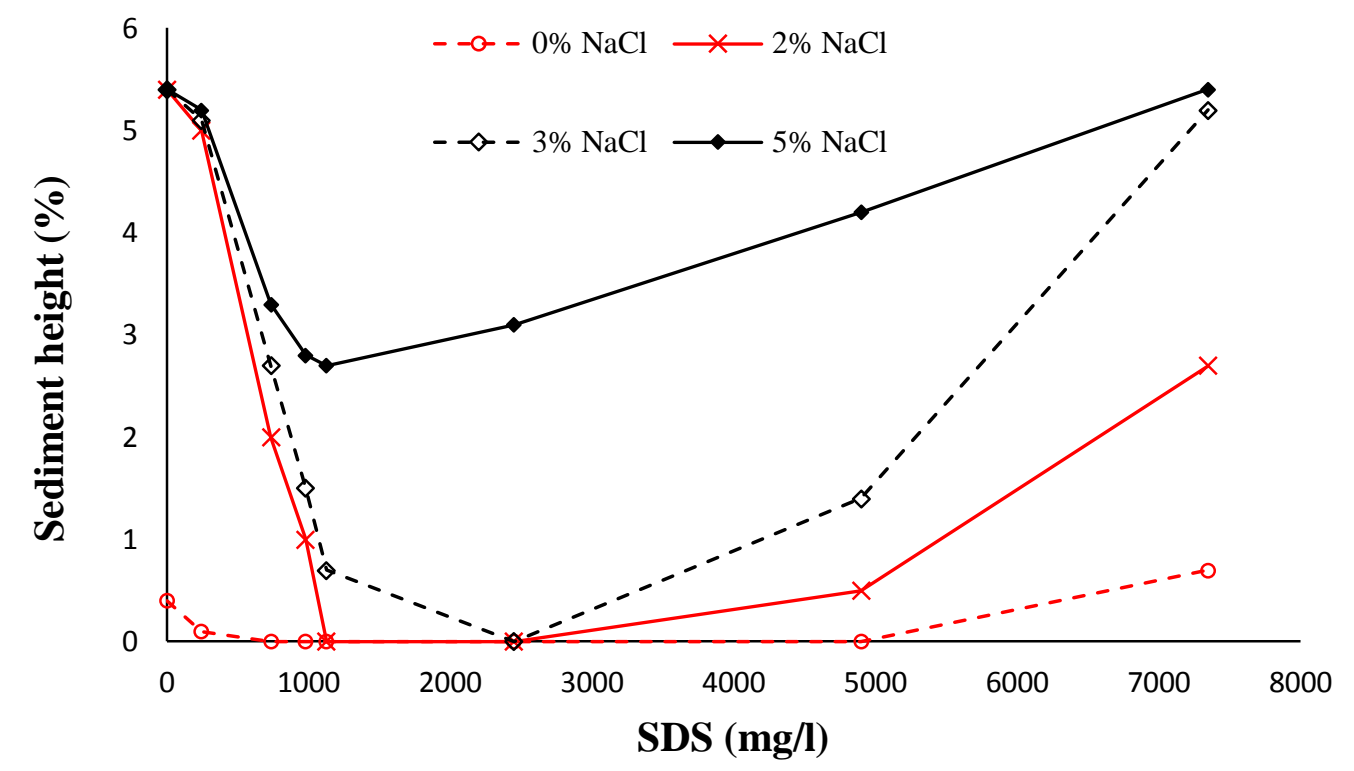

Fig. 6. Sediment height versus SDS concentration after $72 \mathrm{~h}$, at different base fluid salinity for $0.2 \mathrm{wt} \% \mathrm{NP}$ nanofluid at $\mathrm{pH}=7$.

Figure 6 provides the sedimentation trend of silica NPs at different base fluid composition. It is interesting to note that using appropriate concentration of SDS surfactant $(\approx 2450 \mathrm{mg} / 1,1 \mathrm{CMC})$ in the base fluid can stabilize silica NPs even at relatively high salinity ( $\approx 3 \mathrm{wt} \% \mathrm{NaCl})$. However, higher SDS concentration can lead to dramatic increase in particles precipitation referring to unstable nano-suspension. Also it is important to mention that even with the absence of electrolyte (DI water), there was a slight precipitation process of silica NPs with $0 \mathrm{mg} / \mathrm{l}$ SDS. 


\subsection{Interaction between NPs surface and anionic surfactant}

It is of key importance to understand the role and behaviour of anionic surfactant monomers on NP surface before analysing the zeta potential as a function of brine and SDS concentrations.
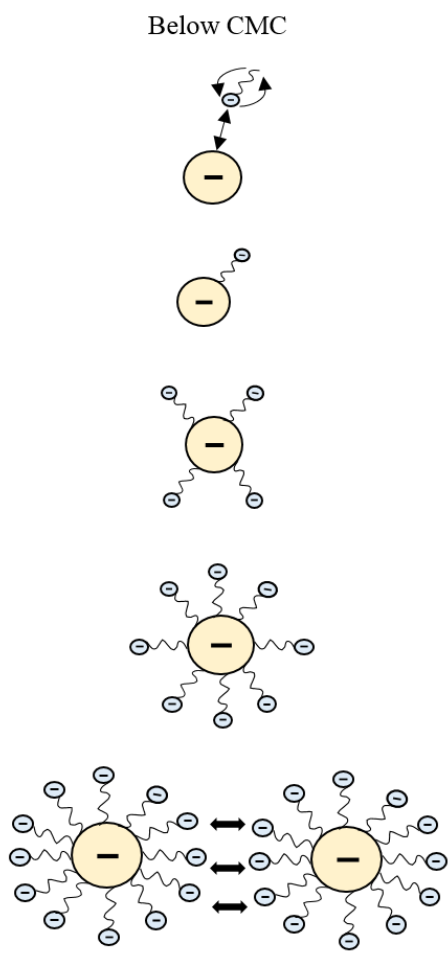
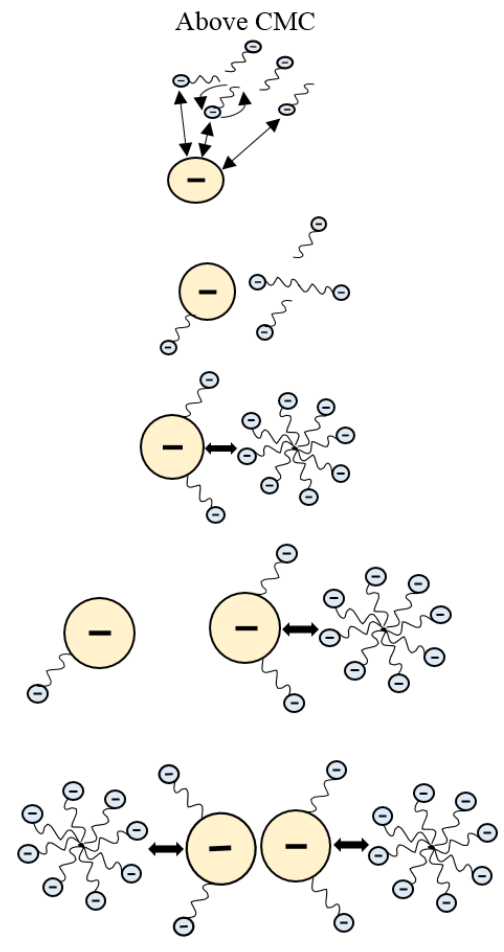

Fig. 7. Mechanisms of anionic molecules adsorption with surfactant concentration before and after reaching the critical micelles concentration (CMC).

Figure 7 suggests the potential behaviour of surfactant monomers at different concentrations. Typically, owing to the high surface area of NP, SDS monomers can be attached to NPs surface by the tail group since the head group of surfactant and the nanoparticles have the similar charge. The number of attached monomers increase with SDS concentration leading to supercharged nanoparticles which drastically increase the repulsive force between these negatively supercharged NPs [19]. However, further increase in SDS concentration ( $\geq \mathrm{CMC}$ ) increases the number of monomers per unit area and leads to the generation of micelles [45]. In this case, it is easy for surfactant monomers to join up together via the hydrophilic tail group instead of being adsorbed to a similarly charged NP. These strongly charged micelles have the ability to repel the negative NPs and forcing them to flocculate gradually (Fig. 7) after the creation of depleted zone around each of them [46]. 
Zeta potential of NP/brine/surfactant system at different salinities and surfactant concentration was measured at $298 \mathrm{~K}$ and constant NPs load $(0.1 \mathrm{wt} \%)$ and acidity of the suspensions $(\mathrm{pH}=6.25)$.

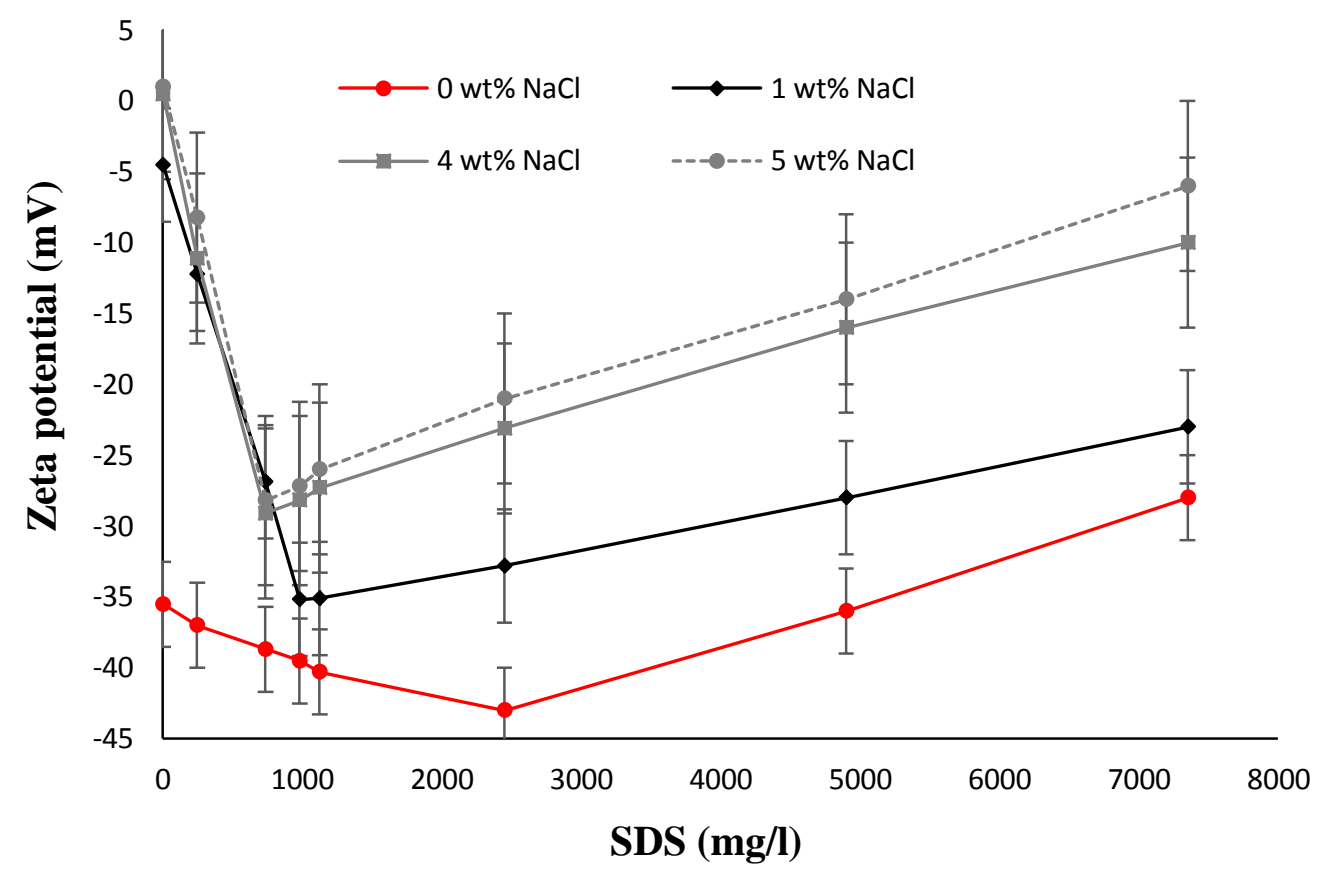

Fig. 8. Effect of electrolyte, and surfactant (SDS) concentration on zeta potential of NPs /brine/surfactant system $\left(0.1 \mathrm{wt} \% \mathrm{SiO}_{2}\right.$ at $\left.\mathrm{pH}=6.25\right)$.

Figure 8 depict that at $\mathrm{pH}=6.25$, and SDS concentration $=0 \mathrm{mg} / \mathrm{l}$, the zeta potential of silica NPs/DI water system was around $-35 \pm 3 \mathrm{mV}$ which corresponds to a stable nanosuspension even with the absence of surfactant. The stability of such suspension is attributed to the efficient repulsive forces between NPs, consistent with Mondragon, Julia, Barba and Jarque [31]. However, it is found that zeta potential of the NP/DIwater/surfactant system first decreased (more negativity) with the increase in SDS concentration (up to SDS concentration $\approx 2500 \mathrm{mg} / \mathrm{l}$ ) and afterwards, zeta potential of the system again increased with SDS concentration. For instance, $\zeta$ decreased to $-43 \mathrm{mV}$ when SDS concentration was $2450 \mathrm{mg} / \mathrm{l}$ then increased gradually with SDS concentration to -28 $\mathrm{mV}$ at $7350 \mathrm{mg} / \mathrm{l}$, SDS.

Different minimum points were recorded depending on the salinity of the base fluid. The dependence of the minimum zeta potential on electrolyte concentration of the nanofluid is related to the effect of salt concentration on CMC value of surfactant [10]. Thus, the 
increase in surfactant concentration higher than CMC decreases the effect of such anionic surfactant on nanofluid stability.

\subsection{Particle size distribution of surface treated NPs.}

The potential of SDS surfactant to limit NPs aggregation was tested via particle size distribution. To accomplish this, we formulated a nano-suspension with $0.1 \mathrm{wt} \% \mathrm{SiO}_{2} \mathrm{NPs}$ dispersed in a base fluid of $1 \mathrm{wt} \% \mathrm{NaCl}$ with two different surfactant concentrations (980 $\mathrm{mg} / \mathrm{l}$ and $4900 \mathrm{mg} / \mathrm{l}$ of SDS dissolved in $1 \mathrm{wt} \% \mathrm{NaCl})$. The particle size was measured using a Zetasizer Nano ZS (Malvern Instruments, UK).

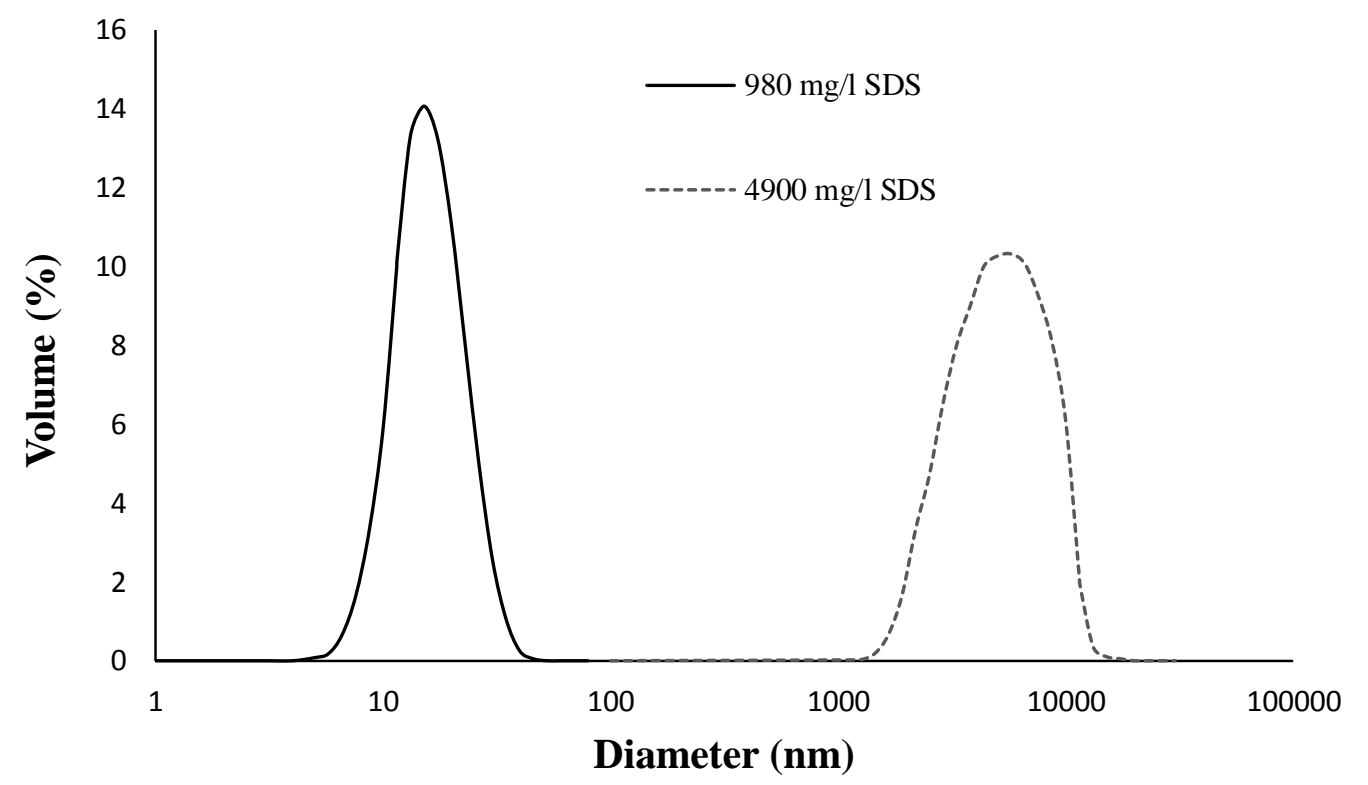

Fig. 9. Compression of particle size distribution of NPs $(0.1 \mathrm{wt} \%)$ with different surfactant concentrations (980 mg/l and $4900 \mathrm{mg} / \mathrm{l}$ of SDS) in the same base fluid (1 wt\% $\mathrm{NaCl})$.

It is clear from Fig. 9 that the addition of a particular amount of anionic surfactant (e.g. $0.4 \mathrm{CMC} ; 980 \mathrm{mg} / \mathrm{l}$, Fig.9) prevents the rapid growth of NPs size and narrows the particle size distribution. This trend is attributed to the formation of a monolayer of surfactant monomers on the particle surface which increases the repulsive force between particles and thus increase the degree of dispersity. In contrast, using high concentration of anionic surfactant (2 CMC; $4900 \mathrm{mg} / \mathrm{l}$, Fig. 9) decreases the dispersity of nanofluid leading to the formation of large aggregates. These results confirm the positive effect of low concentration surfactant on zeta potential (Fig. 8) and the effect of NP and $\mathrm{NaCl}$ concentrations on $\mathrm{CMC}$ 
of surfactant in the base fluid [10]. This is consistent with ShamsiJazeyi, Miller, Wong, Tour and Verduzco [4] who revealed the sensitivity of nano-dispersions ( with DI water) stability to anionic surfactant concentration.

\section{Conclusions}

The use of nanotechnology in many industries particularly subsurface applications is currently an active area of investigation [8, 11, 47, 48]. Stability of nanofluid formulations is the key for the success of nanofluid application in high salinity environments [7, 20]. In this study, the influence of anionic and cationic surfactants on the dispersion stability of saline silica nanofluids was investigated. However, we point out that the results of this study provide a basic framework of optimum surfactant concentration. But, in some practical field applications (e.g. soil decontamination, drilling, carbon geostorage, and enhanced oil recovery), other factors (e.g. temperature, rock type, rock mineralogy, adsorption of surfactant on rock surface) must be taken into account before decision making. Prior to sedimentation measurements, the zeta potentials for different silica nanoparticle (NP)brine-surfactant formulations were measured. Clearly both cationic (CTAB) and anionic (SDS) surfactants had a significant influence on nanofluid stability due to their effect on NP surface charges. Anionic surfactant (SDS), at concentrations below the critical micelles concentration $(\mathrm{CMC})$, stabilized the nanofluid even at high salinity $(5 \mathrm{wt} \% \mathrm{NaCl})$ which is explained by the increase in zeta potentials consistent with literature [45]. In contrast, cationic surfactants (CTAB) accelerated nanoparticle agglomeration at all salinities. Two different mechanisms were highlighted to explain the behavior of cationic and anionic surfactant on the hydrophilic surface of NPs based on charges of hydrophilic silica nanoparticles and the head group of the cationic and anionic surfactant. We thus conclude that addition of low concentrations of anionic surfactants strongly enhances nanofluid stability and enables nanofluid application in saline environments.

\section{References}

[1] R. Tong, H.D. Hemmati, R. Langer, D.S. Kohane, Photoswitchable Nanoparticles for Triggered Tissue Penetration and Drug Delivery, Journal of the American Chemical Society 134(21) (2012) 8848-8855.

[2] S. Baeckkyoung, K. Se Hoon, L. Sungwoo, L. Jaekwan, L. Jin-Kyu, S. Kwang-Sup, Nanofluid transport in a living soft microtube, Journal of Physics D: Applied Physics 48(34) (2015) 345402. 
[3] S.E. Lohse, C.J. Murphy, Applications of Colloidal Inorganic Nanoparticles: From Medicine to Energy, Journal of the American Chemical Society 134(38) (2012) 15607-15620.

[4] H. ShamsiJazeyi, C.A. Miller, M.S. Wong, J.M. Tour, R. Verduzco, Polymer-coated nanoparticles for enhanced oil recovery, Journal of Applied Polymer Science 131(15) (2014) 1-13.

[5] G. Lu, Y.-Y. Duan, X.-D. Wang, Surface tension, viscosity, and rheology of water-based nanofluids: a microscopic interpretation on the molecular level, Journal of Nanoparticle Research 16(9) (2014) 111.

[6] H. Wang, N. Yan, Y. Li, X. Zhou, J. Chen, B. Yu, M. Gong, Q. Chen, Fe nanoparticle-functionalized multi-walled carbon nanotubes: one-pot synthesis and their applications in magnetic removal of heavy metal ions, Journal of Materials Chemistry 22(18) (2012) 9230-9236.

[7] S. Al-Anssari, M. Arif, S. Wang, A. Barifcani, M. Lebedev, S. Iglauer, CO2 geo-storage capacity enhancement via nanofluid priming, International Journal of Greenhouse Gas Control 63 (2017) 2025.

[8] S. Al-Anssari, A. Barifcani, S. Wang, M. Lebedev, S. Iglauer, Wettability alteration of oil-wet carbonate by silica nanofluid, Journal of Colloid and Interface Science 461 (2016) 435-442.

[9] L.N. Nwidee, S. Al-Anssari, A. Barifcani, M. Sarmadivaleh, S. Iglauer, Nanofluids for Enhanced Oil Recovery Processes: Wettability Alteration Using Zirconium Oxide, Offshore Technology Conference Asia, Offshore Technology Conference, Kuala Lumpur, Malaysia, 2016.

[10] S. Al-Anssari, S. Wang, A. Barifcani, S. Iglauer, Oil-water interfacial tensions of silica nanoparticle-surfactant formulations, Tenside Surfactants Detergents 54(4) (2017) 334-341.

[11] S. Al-Anssari, S. Wang, A. Barifcani, M. Lebedev, S. Iglauer, Effect of temperature and SiO2 nanoparticle size on wettability alteration of oil-wet calcite, Fuel 206 (2017) 34-42.

[12] S. Chakraborty, S. Padhy, Anomalous Electrical Conductivity of Nanoscale Colloidal Suspensions, ACS Nano 2(10) (2008) 2029-2036.

[13] B.T. Branson, P.S. Beauchamp, J.C. Beam, C.M. Lukehart, J.L. Davidson, Nanodiamond Nanofluids for Enhanced Thermal Conductivity, ACS Nano 7(4) (2013) 3183-3189.

[14] S. Wu, A. Nikolov, D. Wasan, Cleansing dynamics of oily soil using nanofluids, Journal of Colloid and Interface Science 396 (2013) 293-306.

[15] Y. Liu, C. Sun, T. Bolin, T. Wu, Y. Liu, M. Sternberg, S. Sun, X.-M. Lin, Kinetic Pathway of Palladium Nanoparticle Sulfidation Process at High Temperatures, Nano Letters 13(10) (2013) 4893-4901.

[16] L.P. Dake, Fundamentals of Reservoir Engineering, Elsevier, 1978.

[17] S. Krevor, C. Reynolds, A. Al-Menhali, B. Niu, The Impact of Reservoir Conditions and Rock Heterogeneity on CO2-Brine Multiphase Flow in Permeable Sandstone, Petrophysics 57(1) (2016) 12 18.

[18] G.M. El-Sayed, M.M. Kamel, N.S. Morsy, F.A. Taher, Encapsulation of nano Disperse Red 60 via modified miniemulsion polymerization. I. Preparation and characterization, Journal of Applied Polymer Science 125(2) (2012) 1318-1329.

[19] S. Ahualli, G.R. Iglesias, W. Wachter, M. Dulle, D. Minami, O. Glatter, Adsorption of Anionic and Cationic Surfactants on Anionic Colloids: Supercharging and Destabilization, Langmuir 27(15) (2011) 9182-9192.

[20] T. Sharma, G.S. Kumar, J.S. Sangwai, Comparative effectiveness of production performance of Pickering emulsion stabilized by nanoparticle-surfactant-polymerover surfactant-polymer (SP) flooding for enhanced oil recoveryfor Brownfield reservoir, Journal of Petroleum Science and Engineering 129 (2015) 221-232.

[21] B.P. Binks, M. Kirkland, J.A. Rodrigues, Origin of stabilisation of aqueous foams in nanoparticlesurfactant mixtures, Soft Matter 4(12) (2008) 2373-2382.

[22] Z.G. Cui, Y.Z. Cui, C.F. Cui, Z. Chen, B.P. Binks, Aqueous Foams Stabilized by in Situ Surface Activation of $\mathrm{CaCO} 3$ Nanoparticles via Adsorption of Anionic Surfactant, Langmuir 26(15) (2010) 12567-12574.

[23] S. Limage, J. Krägel, M. Schmitt, C. Dominici, R. Miller, M. Antoni, Rheology and Structure Formation in Diluted Mixed Particle-Surfactant Systems, Langmuir 26(22) (2010) 16754-16761. 
[24] M. Zargartalebi, R. Kharrat, N. Barati, Enhancement of surfactant flooding performance by the use of silica nanoparticles, Fuel 143(0) (2015) 21-27.

[25] B.P. Binks, J.A. Rodrigues, Influence of surfactant structure on the double inversion of emulsions in the presence of nanoparticles, Colloids and Surfaces A: Physicochemical and Engineering Aspects 345(1-3) (2009) 195-201.

[26] R. Atkin, V.S.J. Craig, E.J. Wanless, S. Biggs, Mechanism of cationic surfactant adsorption at the solid-aqueous interface, Advances in Colloid and Interface Science 103(3) (2003) 219-304.

[27] Q. Lan, F. Yang, S. Zhang, S. Liu, J. Xu, D. Sun, Synergistic effect of silica nanoparticle and cetyltrimethyl ammonium bromide on the stabilization of O/W emulsions, Colloids and Surfaces A: Physicochemical and Engineering Aspects 302(1-3) (2007) 126-135.

[28] S. Mahdi Jafari, Y. He, B. Bhandari, Nano-Emulsion Production by Sonication and Microfluidization-A Comparison, International Journal of Food Properties 9(3) (2006) 475-485. [29] G. Petzold, R. Rojas-Reyna, M. Mende, S. Schwarz, Application Relevant Characterization of Aqueous Silica Nanodispersions, Journal of Dispersion Science and Technology 30(8) (2009) 12161222.

[30] M. Shen, D.E. Resasco, Emulsions Stabilized by Carbon Nanotube-Silica Nanohybrids, Langmuir 25(18) (2009) 10843-10851.

[31] R. Mondragon, J.E. Julia, A. Barba, J.C. Jarque, Characterization of silica-water nanofluids dispersed with an ultrasound probe: A study of their physical properties and stability, Powder Technology 224 (2012) 138-146.

[32] J. Vinogradov, M.D. Jackson, Zeta potential in intact natural sandstones at elevated temperatures, Geophysical Research Letters 42(15) (2015) 6287-6294.

[33] M. Kaszuba, D. McKnight, M.T. Connah, F.K. McNeil-Watson, U. Nobbmann, Measuring sub nanometre sizes using dynamic light scattering, Journal of Nanoparticle Research 10(5) (2008) 823829.

[34] B.J. Kirby, E.F. Hasselbrink, Zeta potential of microfluidic substrates: 1 . Theory, experimental techniques, and effects on separations, ELECTROPHORESIS 25(2) (2004) 187-202.

[35] A. Nakamura, H. Furuta, M. Kato, H. Maeda, Y. Nagamatsu, Effect of soybean soluble polysaccharides on the stability of milk protein under acidic conditions, Food Hydrocolloids 17(3) (2003) 333-343.

[36] C. Metin, L. Lake, C. Miranda, Q. Nguyen, Stability of aqueous silica nanoparticle dispersions, Journal of Nanoparticle Research 13(2) (2011) 839-850.

[37] R. Tantra, P. Schulze, P. Quincey, Effect of nanoparticle concentration on zeta-potential measurement results and reproducibility, Particuology 8(3) (2010) 279-285.

[38] Y.V. Li, L.M. Cathles, Retention of silica nanoparticles on calcium carbonate sands immersed in electrolyte solutions, Journal of Colloid and Interface Science 436(0) (2014) 1-8.

[39] D.H. Tsai, S. Kim, T. Corrigan, R.J. Phaneuf, M.R. Zachariah, Electrostatic-directed deposition of nanoparticles on a field generating substrate, Nanotechnology 16(9) (2005) 1856.

[40] E.A. Bayat, R. Junin, A. Samsuri, A. Piroozian, M. Hokmabadi, Impact of Metal Oxide

Nanoparticles on Enhanced Oil Recovery from Limestone Media at Several Temperatures, Energy \& Fuels 28(10) (2014) 6255-6266.

[41] A. Bayat, R. Junin, F. Ghadikolaei, A. Piroozian, Transport and aggregation of Al2O3 nanoparticles through saturated limestone under high ionic strength conditions: measurements and mechanisms, Journal of Nanoparticle Research 16(12) (2014) 1-12.

[42] B.P. Binks, J.A. Rodrigues, W.J. Frith, Synergistic Interaction in Emulsions Stabilized by a Mixture of Silica Nanoparticles and Cationic Surfactant, Langmuir 23(7) (2007) 3626-3636.

[43] Z.G. Cui, L.L. Yang, Y.Z. Cui, B.P. Binks, Effects of Surfactant Structure on the Phase Inversion of Emulsions Stabilized by Mixtures of Silica Nanoparticles and Cationic Surfactant, Langmuir 26(7) (2010) 4717-4724.

[44] Y. Liu, M. Tourbin, S. Lachaize, P. Guiraud, Silica nanoparticles separation from water: Aggregation by cetyltrimethylammonium bromide (CTAB), Chemosphere 92(6) (2013) 681-687. 
[45] G.R. Iglesias, W. Wachter, S. Ahualli, O. Glatter, Interactions between large colloids and surfactants, Soft Matter 7(10) (2011) 4619-4622.

[46] T.F. Tadros, Applied surfactants: principles and applications, John Wiley \& Sons2006.

[47] H. Zhang, T.S. Ramakrishnan, A.D. Nikolov, D. Wasan, Enhanced Oil Recovery (EOR) Driven by Nanofilm Structural Disjoining Pressure: Flooding Experiments and Microvisualization, Energy \& Fuels (2016).

[48] L.N. Nwidee, S. Al-Anssari, A. Barifcani, M. Sarmadivaleh, M. Lebedev, S. Iglauer, Nanoparticles influence on wetting behaviour of fractured limestone formation, Journal of Petroleum Science and Engineering 149 (2017) 782-788. 